University of Nebraska - Lincoln

DigitalCommons@University of Nebraska - Lincoln

Roman L. Hruska U.S. Meat Animal Research

U.S. Department of Agriculture: Agricultural Center

Research Service, Lincoln, Nebraska

2013

\title{
Effects of TMEM154 haplotypes 1 and 3 on susceptibility to ovine progressive pneumonia virus following natural exposure in sheep
}

\author{
K. A. Leymaster \\ US Meat Animal Research Center, kreg.leymaster@ars.usda.gov \\ C. G. Chitko-McKown \\ Roman L. Hruska US Meat Animal Research Center, carol.chitkomckown@ars.usda.gov \\ M. L. Clawson \\ US Meat Animal Research Center, Mike.Clawson@usda.gov
}

G. P. Harhay

Roman L. Hruska US Meat Animal Research Center, gregory.harhay@ars.usda.gov

M. P. Heaton

Roman L. Hruska US Meat Animal Research Center, mike.heaton@usda.gov

Follow this and additional works at: https://digitalcommons.unl.edu/hruskareports

Leymaster, K. A.; Chitko-McKown, C. G.; Clawson, M. L.; Harhay, G. P.; and Heaton, M. P., "Effects of TMEM154 haplotypes 1 and 3 on susceptibility to ovine progressive pneumonia virus following natural exposure in sheep" (2013). Roman L. Hruska U.S. Meat Animal Research Center. 217.

https://digitalcommons.unl.edu/hruskareports/217

This Article is brought to you for free and open access by the U.S. Department of Agriculture: Agricultural Research Service, Lincoln, Nebraska at DigitalCommons@University of Nebraska - Lincoln. It has been accepted for inclusion in Roman L. Hruska U.S. Meat Animal Research Center by an authorized administrator of DigitalCommons@University of Nebraska - Lincoln. 


\title{
Effects of TMEM154 haplotypes 1 and 3 on susceptibility to ovine progressive pneumonia virus following natural exposure in sheep ${ }^{1,2,3}$
}

\author{
K. A. Leymaster, ${ }^{4}$ C. G. Chitko-McKown, M. L. Clawson, G. P. Harhay, and M. P. Heaton \\ USDA-ARS, Roman L. Hruska US Meat Animal Research Center, Clay Center, NE 68933-0166
}

\begin{abstract}
Small ruminant lentiviruses (SRLV) adversely affect production and well-being of sheep and goats throughout much of the world. The SRLV, including ovine progressive pneumonia virus (OPPV) in North America, cause lifetime infections, and management procedures to eradicate or reduce disease prevalence are costly. Variants of ovine transmembrane protein 154 gene (TMEM154) affect susceptibility to OPPV. The primary experimental objective was to estimate additive and dominance effects of TMEM154 haplotypes 1 and 3 on susceptibility to OPPV infection following natural exposure. A group of 187 trial lambs was born and raised by mature, infected ewes to ensure natural exposure to OPPV. Parents of trial lambs were heterozygous for haplotypes 1 and 3, producing lambs with diplotypes " 11 ," "1 3 ," and " 33 ." A group of 20 sentinel lambs was born and raised by mature, uninfected ewes that were diplotype " 11 ." Sentinel lambs had diplotypes " 11 " and " 13 ," being sired by the same set of rams as trial lambs. Trial and sentinel lambs were comingled during the experiment. Lambs were weaned at $60 \mathrm{~d}$ of age, bled $1 \mathrm{wk}$ after weaning, and thereafter at intervals of 4 or 5 wk until 9 mo of age when OPPV
\end{abstract}

infection status was determined by use of a competitive enzyme-linked immunosorbent assay. Only 1 sentinel lamb became infected. Infection status of trial lambs was analyzed using logistic regression procedures to account for the binary nature of infection status and random effects of sires. Effects of sex, type of birth, type of rearing, age of dam, breed type of dam, and sires were not detected $(P>0.20)$. Infection status was affected by diplotype of lamb $(P=0.005)$, with additive $(P=0.002)$ and dominance $(P=0.052)$ effects identified. Predicted probabilities of infection for lambs with diplotypes "1 1," "1 3," and "3 3" were 0.094, 0.323, and 0.346 , respectively. Confidence intervals for probabilities of infection for diplotypes " 13 " and " 33 " were similar, but distinct from diplotype "1 1." These results are consistent with complete dominance of haplotype 3 relative to haplotype 1 . The probability of infection at 9 mo of age for lambs with either diplotype " 13 " or "3 3" averaged 3.56 times that of lambs with diplotype "1 1." Genetic susceptibility to OPPV infection can be reduced by selection to increase the frequency of haplotype 1, resulting in a greater proportion of lambs with diplotype "1 1. ."

Key words: genetic resistance to disease, ovine progressive pneumonia, sheep, small ruminant lentivirus, TMEM154, transmembrane protein

(C) 2013 American Society of Animal Science. All rights reserved.

This article is a U.S. government work, and is not subject to copyright in the United States.
J. Anim. Sci. 2013.91:5114-5121 doi:10.2527/jas2013-6663

\section{INTRODUCTION}

Some strains of visna-maedi virus (VMV) and caprine arthritis-encephalitis virus (CAEV) naturally cross species barriers to infect both sheep and goats (Blacklaws, 2012; Patel et al., 2012). Strains of these viruses are considered phylogenetically as a continuum of a single pathogen and classified as small ruminant lentiviruses (SRLV). Included in this grouping is ovine progressive pneumonia virus (OPPV), the North American form of VMV. Sheep and goat production throughout much of the world are adversely affected

\footnotetext{
${ }^{1}$ The authors gratefully recognize Stacy Bierman, Jacky Carnahan, Gennie Schuller-Chavez, and Jodi Schulte for technical support and the USMARC sheep crew, especially Mike Wallace, Erwin Heiden, and Lynette Anderson, for sheep production and data collection.

${ }^{2}$ Mention of trade name, proprietary product, or specified equipment does not constitute a guarantee or warranty by the USDA and does not imply approval to the exclusion of other products that may be suitable.

${ }^{3}$ USDA is an equal opportunity provider and employer.

${ }^{4}$ Corresponding author: kreg.leymaster@ars.usda.gov

Received May 3, 2013.

Accepted August 5, 2013.
} 
by SRLV infection. Clinical symptoms, including loss of body condition, labored breathing, indurative mastitis, arthritis, and encephalitis, are caused by advancing, persistent inflammation. In the United States, $24 \%$ of sheep were seropositive for OPPV in 2001 (USDA, 2003). Keen et al. (1997a) reported that annual ewe productivity of seropositive ewes was $20 \%$ less than seronegative ewes. The infection is permanent, and management practices to eradicate or reduce prevalence of the disease are expensive and labor intensive.

Heaton et al. (2012) established that variants of ovine transmembrane protein 154 gene (TMEM154) play a central role in susceptibility to OPPV infection. Three haplotypes are commonly found in the United States as well as numerous other countries (Heaton et al., 2013). The relative risk of infection for 2705 sheep sampled from 9 cohorts was 2.85 times greater for sheep with 1 or 2 copies of either haplotype 2 or 3 than sheep homozygous for haplotype 1 (Heaton et al., 2012). Due to low frequencies of haplotypes 2 and 3, it could not be determined if these haplotypes expressed additive or dominance effects on OPPV susceptibility relative to haplotype 1. Estimates of genetic effects are needed to develop efficient selection and mating strategies for industry application. Therefore, we designed an experiment to estimate additive and dominance effects of haplotypes 1 and 3 on susceptibility to OPPV following natural exposure.

\section{MATERIALS AND METHODS}

The Animal Care and Use Committee of the U.S. Meat Animal Research Center (USMARC) approved procedures used in this experiment.

\section{General Design Concepts}

Development of effective procedures to eradicate or reduce the prevalence of OPPV infection is aided by prospective experiments that account for risk factors associated with susceptibility to the disease. In this experiment we controlled three important risk factors: TMEM154 diplotypes of sires and dams, OPPV infection status of dams, and ages of infected dams. Sires and dams were heterozygous for TMEM154 haplotypes 1 and 3, an efficient mating design to estimate additive and dominance effects due to the expected proportions of homozygous and heterozygous progeny. Furthermore, as every mating had the potential to produce lambs of each diplotype, additive and dominance effects were estimated within sire to partially account for polygenic effects. Use of OPPV-infected dams was essential for ensuring natural exposure of lambs to OPPV and accounting for passively acquired antibodies affecting serological data collected on young lambs. Due to the slow and variable progression of the disease, 5- and 6-yr-old infected dams were expected to experimentally standardize, to the extent possible, viral loads presented to lambs through ingestion of infected colostrum and milk.

\section{Sheep Populations and Management}

A USMARC flock of Rambouillet $\times$ Romanov ewes, resulting from reciprocal crosses, was used by Heaton et al. (2012) to validate TMEM154 haplotypes 2 and 3 as risk factors for OPPV infection. These ewes were born in 2005 and 2006, and blood was collected in either July or August of 2010 to determine OPPV serological status and TMEM154 diplotypes. This flock was well suited for the present natural-exposure experiment, as 154 of 271 ewes were both OPPV infected and heterozygous for haplotypes 1 and 3 (diplotype "1 3"). All ewes in the flock were mated to diplotype "1 3" rams. Ewes were mated to 11 crossbred rams (50\% Romanov, 25\% White Dorper, and 25\% Katahdin) in single-sire pens for a 35-d breeding season starting October 6, 2010. Ewes were randomly assigned to rams within diplotype and sire-of-ewe subclasses to address potential population stratification among ewes.

A total of 249 ewes lambed in March and April of 2011, averaging 2.6 lambs born per ewe lambing. No lambs were grafted onto foster ewes. Due partly to the adverse effect of OPPV infection on milk production, as well as the high level of prolificacy, $23 \%$ of lambs were artificially reared, and these lambs were excluded from the experiment. Naturally-reared lambs were born and raised in an open-fronted pole shed under semiconfinement conditions. The pole shed is designed to house 440 ewes and their lambs, has 6 pens, and is used for both drylot lambing and feedlot purposes. Five of the 6 pens were used in the present experiment, with each pen containing about 50 ewes and lambs with similar birth dates. Therefore, infected and uninfected ewes with different TMEM154 diplotypes were comingled in each pen with their lambs. Male lambs were castrated at 2 to 3 wk of age, and tails were docked on all lambs at that time. Lambs were weaned by pen at an average age of $60 \mathrm{~d}$, with a SD of $2.2 \mathrm{~d}$. Ewes were removed from the production facility at weaning, leaving lambs behind at the facility.

A group of 187 trial lambs was established after weaning to provide genotypic and phenotypic data to estimate additive and dominance effects of TMEM154 haplotypes 1 and 3 on susceptibility to infection following natural exposure to OPPV. Trial lambs were born within a 33-d period. All lambs raised by 5- and 6-yr-old dams that were diplotype "1 3" and OPPV infected were used as trial lambs; that is, trial lambs were not selected. Dams were considered infected if percentage inhibition values were $>35 \%$ as tested with a competitive enzyme-linked immunosorbent assay (cELISA; VMRD Inc., Pullman, WA). Each of the 11 sires produced progeny with TMEM154 diplotypes "1 1," 
“1 3," and "3 3." Trial lambs were raised by 109 Rambouillet $\times$ Romanov dams (40 dams were sired by 15 Rambouillet rams, whereas 69 dams were progeny of 16 Romanov rams) and grouped together in a single pen after weaning.

A group of 20 sentinel lambs was also established after weaning to provide OPPV serological data to determine cutoff values for infection classification of trial lambs and, to a lesser extent, the effectiveness of different routes of OPPV transmission. Sentinel lambs were born within an 11-d period and raised by 5 - and 6-yr-old dams that were homozygous for TMEM154 haplotype 1 and uninfected (percentage-inhibition values less than $20 \%$ when sampled in either July or August of 2010). However, these sentinel lambs were exposed to OPPV through weaning due to penning with infected ewes as noted previously. One sentinel lamb was chosen from each of 20 appropriate dams. The 9 wether and 11 ewe sentinel lambs were sired by the same 11 crossbred rams that sired the 187 trial lambs. Sentinel lambs were comingled with trial lambs to form a single cohort of 207 lambs for the remainder of the experiment.

From 1 to 28 wk of age, lambs were given unrestricted access to total-mixed diets that contained $88 \%$ DM and 11.6 MJ of ME per kilogram DM. Crude protein contents of diets were $17.5,14.7$, and $11.9 \%$ from 1 to 10,10 to 23 , and 23 to 28 wk of age, respectively. The cohort of 207 lambs was comingled with the Rambouillet $\times$ Romanov ewes during a 35-d breeding season, starting on September 21, 2011. There were 175 Rambouillet $\times$ Romanov ewes remaining on that date, of which $139(79 \%)$ were classified as OPPV infected in July or August of 2010. The purpose of comingling sheep was to expose lambs to OPPV as would commonly occur in infected flocks during breeding seasons.

Initial blood samples $(10 \mathrm{~mL})$ were collected on May 9, 13, 18, 23, or 26, 1 wk after weaning, from each trial and sentinel lamb via jugular venipuncture using 10$\mathrm{mL}$ syringes. Each sample was transferred immediately after collection into a 3-mL K2 EDTA vacutainer with $5.4 \mathrm{mg}$ anticoagulant and a $5-\mathrm{mL}$ serum vacutainer (Becton, Dickinson and Company, Franklin Lakes, NJ) for subsequent DNA extraction and serum fractionation, respectively. Blood samples $(9 \mathrm{~mL})$ were also drawn, using S-Monovette serum Z syringes (Sarstedt, Newton, NC), from all lambs on June 15, July 20, August 24, September 20, October 27, and December 1 of 2011 to monitor serological trends in anti-OPPV antibodies over time. The average age of lambs at final bleeding was 9 mo.

\section{TMEM154 Genotyping}

The TMEM154 diplotypes of sires, dams, and lambs were determined by use of Sanger sequencing as described in detail by Heaton et al. (2012). Briefly, six mis- sense SNP (L14H, T25I, D33N, E35K, T44M, and N70I) and two frameshift deletion polymorphisms $\left(\mathrm{R}_{4} \mathrm{~A}^{\Delta}\right.$ and E82 $\mathrm{Y}^{\Delta}$ ) were sequenced in the predicted signal peptide and extracellular domains (exons 1 and 2) from PCR fragments amplified from genomic DNA. Sequences from each sheep were scored and recorded manually to assign haplotypes defined by distinct amino-acid sequences due to these polymorphisms. Haplotypes 1 and 3 differ only at position 35: haplotype 1 encodes lysine, whereas haplotype 2 encodes glutamate (Heaton et al., 2012).

The cohort of 207 lambs was also genotyped by a matrix-assisted laser desorption and ionization time-offlight mass spectrometry (MALDI-TOF-MS) assay as previously described (Heaton et al., 2013). Comparison of diplotypes determined by Sanger sequencing and MALDI-TOF-MS procedures revealed three discrepancies which were readily resolved as errors in manual scoring of Sanger sequence data.

\section{Diagnosis of Infection}

Detection of anti-OPPV antibodies in sera of sheep at least 6 mo of age is commonly accepted as an indirect measure of OPPV infection (Cutlip et al., 1988). Serological testing was done at the USMARC using cELISA kits manufactured by VMRD Inc. (Pullman, WA). Although designed to detect antibodies against CAEV in sera of infected goats (Herrmann et al., 2003b), the cELISA test was validated for detection of anti-OPPV antibodies in sera of infected sheep (Herrmann et al., 2003a) and recently has been approved for use in sheep by the USDA. Briefly, the assay uses a horseradish peroxidase-labeled anti-CAEV monoclonal antibody that competes with antibodies present in undiluted sheep serum for the CAEV antigen bound to the microtiter plate. Conversion of a chromogenic substrate to a colored product by the peroxidase allows measurement of competitive binding activity to the antigen. Optical density values are used to calculate percentage inhibition of monoclonal antibody binding. The cELISA kits manufactured by VMRD Inc. (Pullman, WA) have relatively high sensitivity due to the use of undiluted serum, allowing detection of serum with low antibody titers to CAEV (Herrmann et al., 2003b).

The Rambouillet $\times$ Romanov dams were each tested once using the cELISA assay (Heaton et al., 2012). Serum samples collected from the cohort of 207 lambs on each sample date were tested in duplicate to reduce errors in measurement. The difference between the two percentage inhibition values for each lamb was calculated. The distribution of differences within a sample date was tested for deviations from normality using goodness-of-fit statistics. Sera with suspect values were tested again in duplicate, with the second pair of percentage inhibition values replacing the initial data. Final 
values were averaged for analytical purposes. The infection status of lambs was based on serological data associated with the final sample date of December 1, 2011 to allow for the decline of passively acquired antibodies.

\section{Statistical Analysis}

Serological data collected on sentinel lambs were analyzed with the MIXED procedure of SAS (SAS Inst. Inc., Cary, NC) to calculate the residual SD after fitting effects of sample date. The cutoff value to determine OPPV infection was defined as percentage inhibition values greater than two residual SD above the mean of sentinel lambs. This method is similar to that used by Herrmann et al. (2003a) to validate the cELISA assay for detection of anti-OPPV antibodies in sheep.

Infection status (infected or uninfected) of trial lambs was analyzed using logistic regression procedures (GLIMMIX; SAS Inst. Inc.) to account for the binary nature of infection status and random effects of sires. The logit link function was used and the estimation technique was residual pseudo-likelihood. Effects of lamb sex (ewe and wether; $P=0.87$ ), type of birth (single, twin, triplet, and quadruplet; $P=0.21$ ), and type of natural rearing to weaning (single, twin, and triplet; $P=$ 0.29 ) were fitted in exploratory models but subsequently deleted due to lack of statistical significance. The final model included fixed effects of age of dam (5 and $6 \mathrm{yr}$ ), reciprocal cross of dam (Rambouillet rams $\times$ Romanov dams and Romanov rams $\times$ Rambouillet dams) and TMEM154 diplotype of lamb ("1 1," "1 3," and "3 3") and random effects of sires of lambs. These effects were incorporated into the experimental design and therefore included in the statistical model regardless of levels of significance. Linear contrasts of effects of diplotypes "1 1 ," "1 3 ," and " 33 " were used to estimate levels of significance for additive $(-1,0,1)$ and dominance $(-0.5$, $1,-0.5)$ effects. Least-squares means of TMEM154 diplotypes on the logit scale were transformed to the raw scale (inverse logit scale) to give predicted probabilities of OPPV infection.

\section{RESULTS}

\section{Sentinel Lambs}

Sentinel lambs did not passively acquire anti-OPPV antibodies or become infected, with 2 exceptions (Fig. 1). One lamb, diplotype " 11 ," had a notably high percentage inhibition value at the first sample date but declined rapidly thereafter, a pattern consistent with the presence of passively acquired antibodies against OPPV, but not infection. A blood sample drawn from the dam of this lamb in October 2011 revealed that the dam was infected with

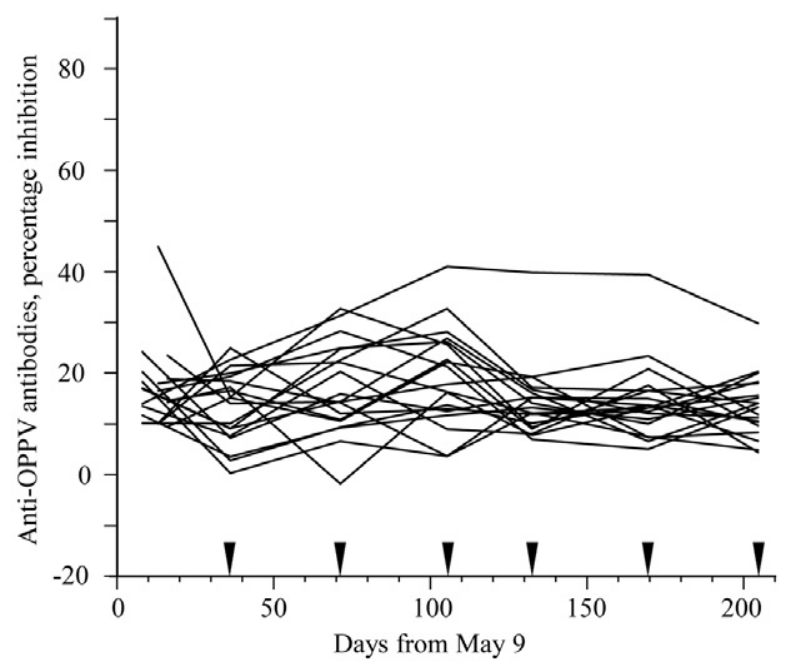

Figure 1. Raw serological data (ovine progressive pneumonia virus, OPPV) collected on sentinel lambs. The first blood samples were drawn from lambs on May 9. Triangles indicate the last 6 sample dates of June 15, July 20, August 24, September 20, October 27, and December 1, 2011.

OPPV (62.9\% inhibition) at that time. We reasoned that the dam was likely infected before giving birth in March 2011 and transmitted anti-OPPV antibodies to her lamb. Another lamb, diplotype "1 3 ," initially had typical values for percentage inhibition that subsequently increased over time. This is the expected pattern for lambs that do not receive passively acquired antibodies against OPPV, but become infected and in time produce actively acquired antibodies. There was no conclusive evidence that the dam of this lamb was infected (21.0\% inhibition) when sampled in October 2011, consistent with the absence of passively acquired antibodies in the serum of her lamb $1 \mathrm{wk}$ after weaning. Thus, this lamb likely became infected due to exposure to OPPV from infected flock mates. The number of uninfected and infected sentinel lambs by TMEM154 diplotype is given in Table 1.

Serological data collected on the 18 sentinel lambs that did not reveal either passively or actively acquired antibodies against OPPV were analyzed to define the cutoff value for infection status of trial lambs. The mean and the residual SD (pooled within sample dates, $119 \mathrm{df}$ ) were 10.7 and $6.07 \%$ inhibition, respectively, giving a cutoff value of $22.8 \%$ inhibition (mean plus two residual SD). This value is in close agreement with the cutoff value of $20.9 \%$ inhibition reported by Herrmann et al. (2003a). Trial lambs with final percentage inhibition values less than 22.8 were classified as uninfected, whereas lambs with values $>22.8$ were considered infected.

\section{Trial Lambs}

The vast majority of uninfected lambs, regardless of TMEM154 diplotype, received passively acquired antiOPPV antibodies via natural exposure to their infected 
Table 1. Number of sentinel and trial lambs by TMEM $154^{1}$ diplotype and infection status at 9 mo of age

\begin{tabular}{lccccccc}
\hline \hline & \multicolumn{3}{c}{ Sentinel } & & \multicolumn{3}{c}{ Trial } \\
\cline { 2 - 3 } TMEM154 & \multicolumn{2}{c}{ Infection status } & & & \multicolumn{2}{c}{ Infection status } & \\
\cline { 2 - 3 } diplotype & Uninfected Infected & Total & & Uninfected & Infected & Total \\
\hline "1 1" & 10 & 0 & 10 & & 50 & 6 & 56 \\
"13" & 9 & 1 & 10 & & 47 & 24 & 71 \\
"3 3" & - & - & - & & 38 & 22 & 60 \\
\hline
\end{tabular}

${ }^{1}$ Transmembrane protein 154 gene.

dams, resulting in high initial values for percentage inhibition that decreased with time to eventually fall below the cutoff value (Fig. 2). However, passive transfer, as measured by detection of anti-OPPV antibodies 1 wk after weaning, apparently failed for 8 lambs, despite being born to dams with percentage inhibition values greater than 50. The serological patterns for these 8 lambs were similar to the 18 sentinel lambs, with means of 11.0 and $10.7 \%$ inhibition, respectively.

Some lambs of each TMEM154 diplotype became infected by 9 mo of age (Fig. 2). Percentage inhibition values of infected lambs were similar to uninfected lambs for at least the first 2 sample dates, but then began to diverge as infected lambs presumably started to produce actively acquired antibodies against OPPV. As the cELISA assay does not distinguish between passively and actively acquired anti-OPPV antibodies, percentage inhibition values of infected lambs at intermediate sample dates may reflect both sources of antibodies. Percentage inhibition values on the final sample date were more variable among infected than uninfected lambs.

The number of trial lambs by TMEM154 diplotype and infection status also is shown in Table 1 and results of analysis of infection status are summarized in Table 2. Fixed effects of age of dam $(P=0.633)$ and reciprocal cross of dam $(P=0.205)$ on infection status were not detected. Likewise, random effects of sires did not influence susceptibility of lambs to infection $(P>0.27$, not tabulated). Given that all sires were TMEM154 diplotype "1 3," the experiment failed to detect additional genetic effects on infection status.

Infection status was affected by TMEM154 diplotypes of lambs $(P=0.005$, Table 2$)$. The $2 \mathrm{df}$ test for diplotype effects was partitioned into orthogonal contrasts to estimate additive and dominance effects, which each influenced susceptibility to infection $(P=0.002$ and $P$ $=0.052$, respectively). Predicted probabilities of OPPV infection and their confidence intervals for each diplotype are given in Table 3. Predicted probabilities of infection for lambs with diplotypes "1 1," "1 3," and "3 3" $(0.094,0.323$, and 0.346 , respectively) agree well with percentages of infected trial lambs calculated from frequency data shown in Table $1(0.107,0.338$, and 0.367 , respectively). The confidence intervals are similar for diplotypes "1 3" and "3 3," but do not overlap with the confidence interval for diplotype " 11 ." These predicted probabilities of infection are consistent with complete dominance of haplotype 3 relative to haplotype 1 . The probability of infection at 9 mo of age for lambs with either diplotype "1 3 " or "3 3 " averaged 3.56 times that of lambs with diplotype " 11 ."

\section{DISCUSSION}

The widespread and adverse impacts of SRLV on production and well-being of sheep and goats provide justification for ongoing research efforts in numerous countries. Reviews of SRLV have addressed pathology, symptoms, diagnosis, transmission, risk factors, productivity, and control guidelines, including eradication (Blacklaws et al., 2004; Peterhans et al., 2004; Reina et al., 2009; Blacklaws and Harkiss, 2010; Blacklaws, 2012; Patel et al., 2012). The experiments reviewed often have been retrospective in nature, particularly for investigation of risk factors potentially associated with disease prevalence. Interpretation of results from retrospective experiments may be complicated by unknown confounding effects, such as history of exposure to SRLV or genetic aspects of susceptibility. Researchers have proposed the existence of within-breed genetic variation for susceptibility to SRLV infection (Berriatua et al., 2003; Alvarez et al., 2005; Leginagoikoa et al., 2006a). The discovery that TMEM154 variants significantly affected susceptibility of sheep to OPPV infection (Heaton et al., 2012), combined with the wide global distribution of 3 haplotypes (Heaton et al., 2013), suggest that interpretation of some previous experimental results might have changed if TMEM154 diplotypes and their effects were known at the time of research. Recently, White et al. (2012) reported that accounting for TMEM154 diplotype effects did influence results of a genome-wide association of SNP with OPPV serological status.

The present experimental results provide conclusive evidence that TMEM154 influences susceptibility to OPPV infection. The predicted probability of infection for lambs with diplotypes " 13 " and " 33 " averaged 3.56 times that of lambs with diplotype " 11 ." Heaton et al. (2012) estimated relative risk in 9 cohorts of sheep at least $3 \mathrm{yr}$ of age, reporting an overall value of 2.85 for sheep with 1 or 2 copies of either haplotypes 2 or 3 compared to sheep with diplotype "1 1 ." Detection of diplotype effects by 9 mo of age was not anticipated in the present research, but likely was aided by exposure of all lambs to substantial viral loads in colostrum and milk of mature, infected ewes. Serological data will continue to be collected on trial ewes through $4 \mathrm{yr}$ of age to test diplotype effects on age at seroconversion and to estimate probabilities of infection at maturity. 
$\underline{\text { Uninfected }}$
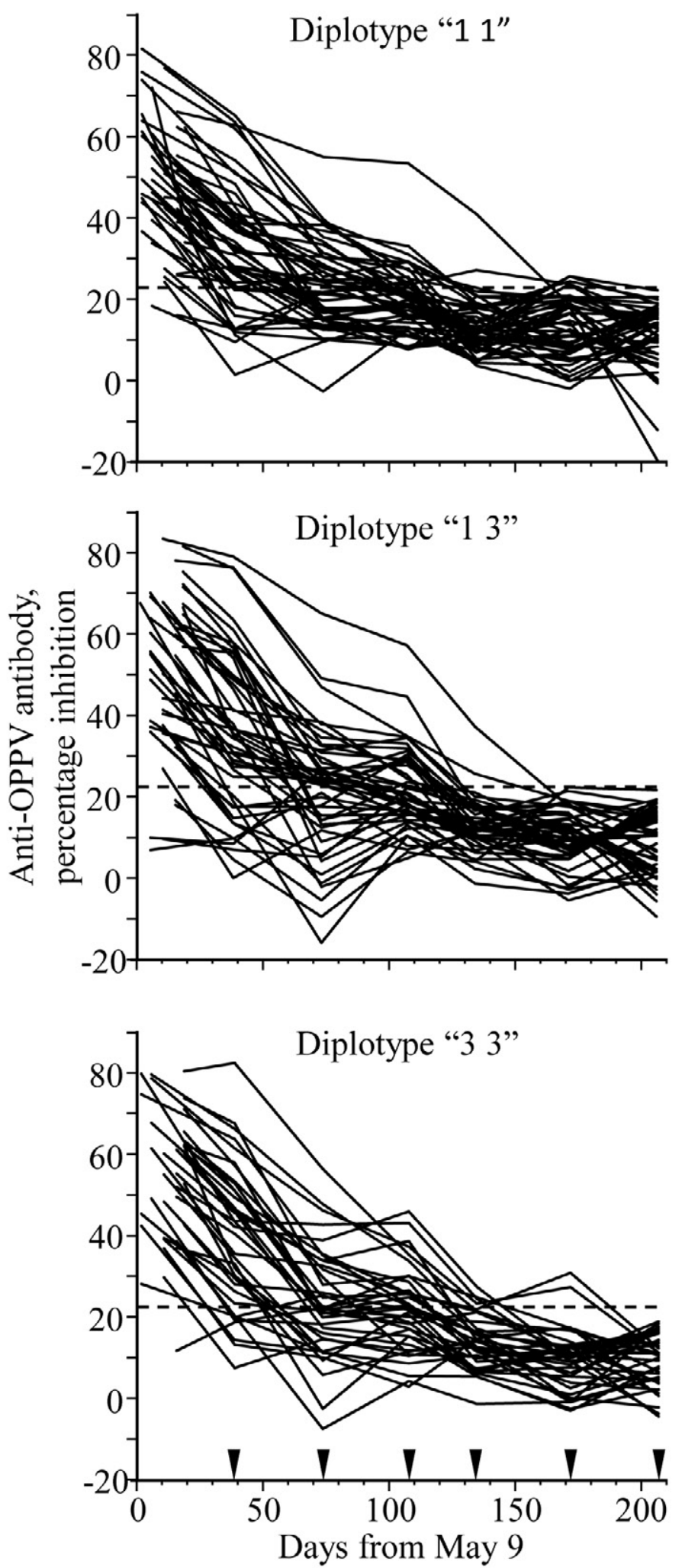

$\underline{\text { Infected }}$
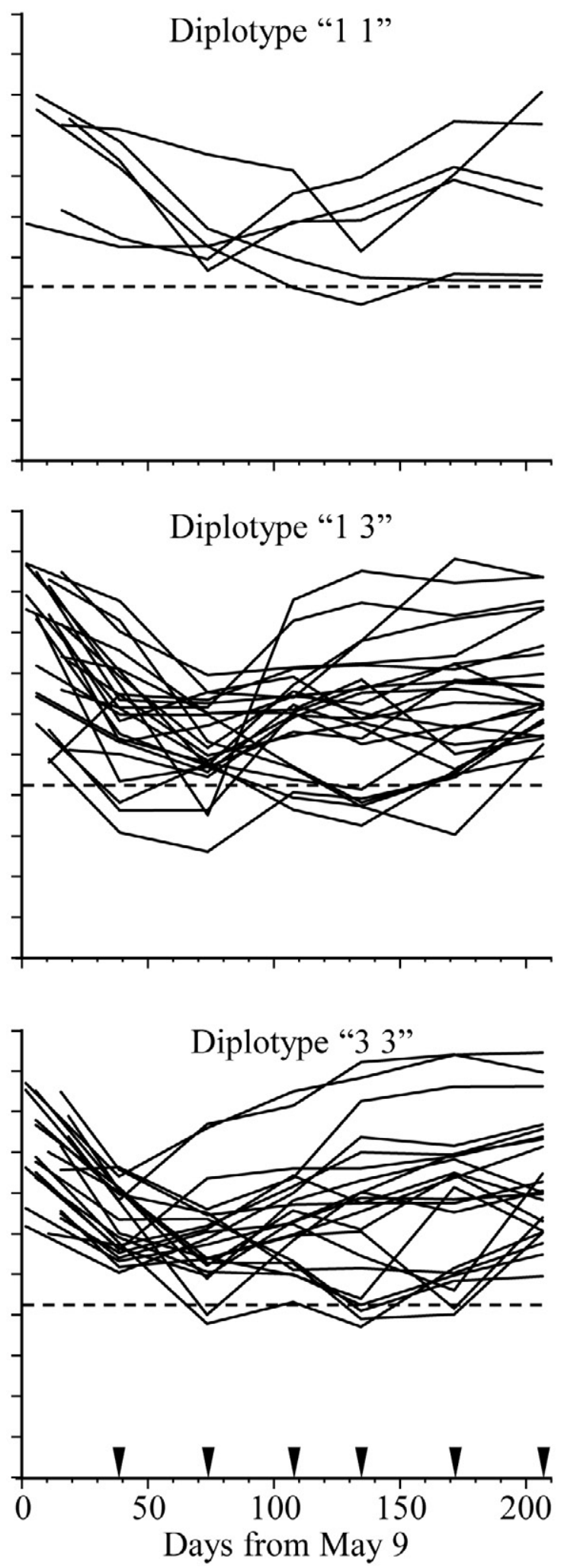

Figure 2. Raw serological data (ovine progressive pneumonia virus, OPPV) collected on uninfected and infected trial lambs with TMEM154 diplotypes "1 1," "1 3," and "3 3." The first blood samples were drawn from lambs on May 9. Triangles indicate the last 6 sample dates of June 15, July 20, August 24, September 20, October 27, and December 1, 2011. Dashed lines mark the cutoff value used to determine infection status on the last sample date. 
Table 2. $P$-values for fixed sources of variation and additive and dominance effects on infection status

\begin{tabular}{lc}
\hline \hline Item & $P$-value \\
\hline Age of dam & 0.633 \\
Reciprocal cross of dam & 0.205 \\
TMEM154 diplotype of lamb & 0.005 \\
Additive & 0.002 \\
Dominance & 0.052 \\
\hline
\end{tabular}

The experiment was designed to estimate additive and dominance effects of haplotypes 1 and 3, as previous research could only exclude dominance effects of haplotype 1 due to few sheep being homozygous for haplotype 3 (Heaton et al., 2012). Tests of linear contrasts of diplotype effects established that haplotype 3 is dominant to haplotype 1. Genetic susceptibility to OPPV infection can be reduced by selection to increase the frequency of haplotype 1 and decrease the frequency of haplotype 3 , resulting in a greater proportion of lambs with diplotype " 11 ." To make certain that the vast majority of lambs have low genetic susceptibility to infection (diplotype "1 1 "), the frequency of haplotype 1 must be high in both sires and dams due to the recessive nature of haplotype 1 .

From a biological perspective, transmission of SRLV occurs by maternal and nonmaternal routes. Maternal transmission between a dam and her lamb(s) is caused primarily by infected colostrum, milk, or respiratory secretions from the dam, whereas nonmaternal transmission is believed largely due to inhalation by naïve sheep of respiratory secretions from infected sheep in the flock (Blacklaws et al., 2004; Peterhans et al., 2004). The perceived relative importance of these routes of transmission has changed over time as understanding of transmission has progressed. Infected colostrum and milk were initially thought to be the primary causes of infection (e.g., Cutlip et al., 1988; Keen et al., 1997b) and drove development of management procedures to control the disease in many countries (Peterhans et al., 2004; Reina et al., 2009). Evidence has accumulated to indicate that maternal transmission causes a lower proportion of infection in mature sheep than does nonmaternal transmission (Berriatua et al., 2003; Alvarez et al., 2005; Leginagoikoa et al., 2006a, 2006b; Herrmann-Hoesing et al., 2007; Broughton-Neiswanger et al., 2010). Berriatua et al. (2003) concluded that if nonmaternal transmission is not prevented, then the lifetime risk of infection in a population is not increased by maternal transmission. Stated differently, nonmaternal transmission among adult sheep has a greater impact on lifetime infection than maternal transmission from infected dams to their progeny.
Table 3. Predicted probability of infection and $95 \%$ confidence interval by TMEM154 ${ }^{1}$ diplotype of lamb

\begin{tabular}{lcc}
\hline \hline TMEM154 diplotype & Probability of infection & Confidence interval \\
\hline "1 1" & 0.094 & $0.039,0.205$ \\
"1 3" & 0.323 & $0.215,0.453$ \\
"3 3" & 0.346 & $0.225,0.491$ \\
\hline \multicolumn{2}{c}{ "Transmembrane protein 154 gene. }
\end{tabular}

Serological data from the present experiment support the current understanding of importance of alternative routes of transmission. With a single exception, sentinel lambs were born and raised by uninfected dams, but comingled with infected ewes to weaning and with infected lambs to 9 mo of age. Nonmaternal exposure to OPPV caused 1 of 10 diplotype "1 3" lambs to become infected by 9 mo of age, whereas none of the diplotype "1 1" lambs were infected. Trial lambs were born and raised by infected dams and thus exposed to OPPV through both maternal and nonmaternal routes of transmission. The combined effects of maternal and nonmaternal transmission to 9 mo of age resulted in predicted probabilities of infection of $9.4,32.3$, and $34.6 \%$ for trial lambs with diplotypes "1 1 ," "1 3 ," and " 33 ," respectively. Given the low infection rate of sentinel lambs due to nonmaternal transmission, one can infer that maternal transmission was the predominant cause of infection in trial lambs. However, $67 \%$ of the genetically mostsusceptible lambs (diplotype "1 3" and " 3 3") that were raised by infected dams were not infected by 9 mo of age. Furthermore, $90 \%$ of the genetically least-susceptible lambs (diplotype "1 1") did not become infected by 9 mo of age, even when raised by mature, infected dams.

As described herein, dams of sentinel and trial lambs originally were part of a flock of Rambouillet $\times$ Romanov ewes at USMARC. In that flock, 210 of 217 genetically-susceptible ewes $(97 \%)$ were infected with OPPV by 4 or 5 yr of age (Heaton et al., 2012, Table 3 $\mathrm{S} 2$ ). In our production system, maternal transmission can, at most, account for one-third of lifetime infections. Therefore, the primary cause of lifetime infection is likely due to nonmaternal exposure that occurs after naïve ewes join a flock of infected breeding ewes.

\section{LITERATURE CITED}

Alvarez, V., J. Arranz, M. Daltabuit-Test, I. Leginagoika, R. A. Juste, B. Amorena, D. de Andres, L. L. Lujan, J. J. Badiola, and E. Berriatua. 2005. Relative contribution of colostrum from maedi-visna virus (MMV) infected ewes to MVV-seroprevalence in lambs. Res. Vet. Sci. 78:237-243.

Berriatua, E., V. Alvarez, B. Extramiana, L. Gonzalez, M. Daltabuit, and R. Juste. 2003. Transmission and control implications of seroconversion to maedi-visna virus in Basque dairy-sheep flocks. Prev. Vet. Med. 60:265-279. 
Blacklaws, B. A. 2012. Small ruminant lentiviruses: Immunopathogenesis of visna-maedi and caprine arthritis and encephalitis virus. Comp. Immunol. Microbiol. Infect. Dis. 35:259-269.

Blacklaws, B. A., E. Berriatua, S. Torsteinsdottir, N. J. Watt, D. de Andres, D. Klein, and G. D. Harkiss. 2004. Transmission of small ruminant lentiviruses. Vet. Microbiol. 101:199-208.

Blacklaws, B. A., and G. D. Harkiss. 2010. Small ruminant lentiviruses and human immunodeficiency virus: Cousins that take a long view. Curr. HIV Res. 8:26-52.

Broughton-Neiswanger, L. E., S. N. White, D. P. Knowles, M. R. Mousel, G. S. Lewis, D. R. Herndon, and L. M. HerrmannHoesing. 2010. Non-maternal transmission is the major mode of ovine lentivirus transmission in a ewe flock: A molecular epidemiology study. Infect. Genet. Evol. 10:998-1007.

Cutlip, R. C., H. D. Lehmkuhl, M. J. F. Schmerr, and K. A. Brogden. 1988. Ovine progressive pneumonia (maedi-visna) in sheep. Vet. Microbiol. 17:237-250.

Heaton, M. P., M. L. Clawson, C. G. Chitko-McKown, K. A. Leymaster, T. P. L. Smith, G. P. Harhay, S. N. White, L. M. Herrmann-Hoesing, M. R. Mousel, G. S. Lewis, T. S. Kalbfleisch, J. E. Keen, and W. W. Laegreid. 2012. Reduced lentivirus susceptibility in sheep with TMEM154 mutations. PLoS Genet. 8:e1002467.

Heaton, M. P., T. S. Kalbfleisch, D. T. Petrik, B. Simpson, J. W. Kijas, M. L. Clawson, C. G. Chitko-McKown, G. P. Harhay, and K. A. Leymaster, and the International Sheep Genomics Consortium. 2013. Genetic testing for TMEM154 mutations associated with lentivirus susceptibility in sheep. PLoS ONE 8:e55490.

Herrmann, L. M., W. P. Cheevers, K. L. Marshall, T. G. McGuire, M. M. Hutton, G. S. Lewis, and D. P. Knowles. 2003a. Detection of serum antibodies to ovine progression pneumonia virus in sheep by using caprine arthritis-encephalitis virus competitiveinhibition enzyme-linked immunosorbent assay. Clin. Diagn. Lab. Immunol. 10:862-865.

Herrmann, L. M., W. P. Cheevers, T. C. McGuire, D. S. Adams, M. M. Hutton, W. G. Gavin, and D. P. Knowles. 2003b. Competitive-inhibition enzyme-linked immunosorbent assay for detection of serum antibodies to caprine arthritis-encephalitis virus: Diagnostic tool for successful eradication. Clin. Diagn. Lab. Immunol. 10:267-271.
Herrmann-Hoesing, L. M., G. H. Palmer, and D. P. Knowles. 2007. Evidence of proviral clearance following postpartum transmission of an ovine lentivirus. Virology 362:226-234.

Keen, J. E., L. L. Hungerford, E. T. Littledike, T. E. Wittum, and J. Kwang. 1997a. Effect of ewe ovine lentivirus infection on ewe and lamb productivity. Prev. Vet. Med. 30:155-169.

Keen, J. E., L. L. Hungerford, T. E. Wittum, J. Kwang, and E. T. Littledike. 1997b. Risk factors for seroprevalence of ovine lentivirus in breeding ewe flocks in Nebraska, USA. Prev. Vet. Med. 30:81-94.

Leginagoikoa, I., M. Daltabuit-Test, V. Alvazrez, J. Arranz, R. A. Juste, B. Amorena, D. de Andres, L. L. Lujan, J. J. Badiola, and E. Berriatua. 2006a. Horizontal maedi-visna virus (MVV) infection in adult dairy-sheep raised under varying MVV-infection pressures investigated by ELISA and PCR. Res. Vet. Sci. 80:235-241.

Leginagoikoa, I., R. A. Juste, J. Barandika, B. Amorena, D. de Andres, L. Lujan, J. Badiola, and E. Berriatua. 2006b. Extensive rearing hinders maedi-visna virus (MMV) infection in sheep. Vet. Res. 37:767-778.

Patel, J. R., J. G. M. Heldens, T. Bakonyi, and M. Rusvai. 2012. Important mammalian veterinary viral immunodiseases and their control. Vaccine 30:1767-1781.

Peterhans, E., T. Greenland, J. Badiola, G. Harkiss, G. Bertoni, B. Amorena, M. Eliaszewicz, R. A. Juste, R. Krabnig, J. P. Lafont, P. Lenihan, G. Petursson, G. Pritchard, J. Thorley, C. Vitu, J. F. Mornex, and M. Pepin. 2004. Routes of transmission and consequences of small ruminant lentiviruses (SRLVs) infection and eradication schemes. Vet. Res. 35:257-274.

Reina, R., E. Berriatua, L. Lujan, R. Juste, A. Sanchez, D. de Andres, and B. Amorena. 2009. Prevention strategies against small ruminant lentiviruses: An update. Vet. J. 182:31-37.

USDA. 2003. Ovine progressive pneumonia: Awareness, management, and seroprevalence. USDA, APHIS, Veterinary Services, Fort Collins, CO.

White, S. N., M. R. Mousel, L. M. Herrmann-Hoesing, J. O. Reynolds, K. A. Leymaster, H. L. Neibergs, G. S. Lewis, and D. P. Knowles. 2012. Genome-wide association identifies multiple genomic regions associated with susceptibility to and control of ovine lentivirus. PLoS ONE 7:e47829. 